\title{
Design of Compact Dual Band Circular Polarized Micro-strip Antenna for High Efficiency WLAN 802.11ax-2019
}

\author{
Syed Muhammad Ali \\ Department of Computer System Engineering, University of Engineering and Technology, Peshawar, Pakistan
}

\begin{tabular}{l} 
Article Info \\
\hline Article history: \\
Received Jun 15, 2018 \\
Revised Jul 31, 2018 \\
Accepted Aug 16, 2018 \\
\hline
\end{tabular}

Keywords:

Axial ratio

Circular Polarization

Directivity

Micro strip antennas

Return loss

\begin{abstract}
Design of antennas for the latest upcoming standards of WLAN is considered as a key challenge in the RF Communication Engineering. Micro-strip antennas are supposed to have some quality features in mobile and wireless communication systems. Their weight and size are reduced and they are capable of having low power capacity. All these interesting features enabled these type of antennas suitable for the communication of IEEE 802.11ax2019 high speed WLANs. Shape of these antennas can be designed in an efficient manner to achieve required gain and bandwidth. In this paper the concept of circular polarization has been introduced along with compact design of antennas in order to achieve return loss and axial ratio of less than $10 \mathrm{~dB}$ and $3 \mathrm{~dB}$ respectively. Antenna has been designed and simulated on CST MW studio software and usage of dual bands 2.4 and $5.2 \mathrm{GHz}$ having circular polarization is properly elucidated for 802.11ax-2019.
\end{abstract}

Copyright $@ 2018$ Institute of Advanced Engineering and Science. All rights reserved.

Corresponding Author:

Department of Computer System Engineering,

University of Engineering and Technology,

Peshawar, Pakistan.

Email: syed6513@gmail.com

\section{INTRODUCTION}

In today's era of wireless communication, there is a greater demand of producing low profile, low size compact antennas that can handle large spectrum of frequencies. As the frequency increases, size of the antenna reduces. Micro-strip antennas are used to process ultra-high frequency band in cell phone receiver or on satellite radio but despite of this have shown some constraints because of limited bandwidth. This issue can be addressed by designing without a dielectric substrate or having some modifications in the parameter design, therefore these antennas have received much attention in radar, satellite and most recently in WLAN and WPAN networks. The notion of circular polarization is being introduced in [1] to cover the loss caused by misalignment between signals and of receiving antenna. CP is generated using two orthogonal modes having phase difference of $90^{\circ}$ between them. In [2] antenna was designed to improve ground plane structure having $\mathrm{T}$ shaped strip, a vertical stub and a slit to achieve CP. Monopole antenna was designed [3] having L shaped slit and rectangular patch with dual band circular polarization. Hexagonal shaped antenna was designed with $\mathrm{L}$ shaped stub to achieve CP [4]. It is however not easy for the dual band CP antenna to improve the separation between channels having co-polarization effect in different bands [5]. Design of the single feed antennas and dual band CP antennas along with configurations have been proposed in [6-8]. In [9] realization of the $\mathrm{CP}$ radiation in two different bands were elaborated having a single patch in multi resonance modes. Similarly, Dual band CP with dual sense stacked patch antenna with a small frequency ratio for UHF RFID Reader applications in [10] was proposed and designed. In this paper it was compelling to design a dual frequency based CP micro-strip antenna to improve the performance of high efficiency WLANS 802.11ax technology. All the performance improvements will be based on radiation pattern, bandwidth, return loss, axial ratio and gain. 


\section{PARAMETERS OF THE DESIRED ANTENNA}

The idea to comprehend the design of CP Antenna was first illustrated by the design of circular patch [11] as given in the equations below

$$
f_{\text {res }}=\sqrt{\frac{1.841 c}{2 \pi r_{e f f e^{\varepsilon_{r}}}}}
$$

$f_{\text {res }}$ is the resonance frequency of $\mathrm{CP}$ antenna whereas " $c$ is the velocity of light and $r_{\text {effe }}$ is the effective radius of the circular patch in CP antenna [11].

$$
r_{e f f e}=a \cdot \sqrt{\left(1+\frac{2 h}{\pi a \varepsilon_{r}}\right)\left\{\ln \left(\frac{\pi a}{2 h}\right)+1.772\right\}}
$$

Considering above formula, " $h$ " is called as the dielectric height and " $a$ "as the actual radius of the circular patch.

Figure 1 and 2 show demonstrates that there are two patches of copper which are needed to be considered for our approach of antenna design. Larger patch is considered to be a resonant radiator having frequency of $5.2 \mathrm{GHz}$ and smaller patch to be also a resonant radiator of having frequency of $2.4 \mathrm{GHz}$ respectively.FR4 is the material chosen for two di-electric substrates. In order to enhance flexibility for impedance matching, the lower patch has to be moved by positions Xa and Ya. A coaxial probe of 50 $\Omega$ SMA is used for the feed structure mounted at the coordinates of $(\mathrm{X}, \mathrm{Y})$ and thus making an angle of $45^{\circ}$ from $\mathrm{X}$ axis and $\mathrm{Y}$-axis respectively.

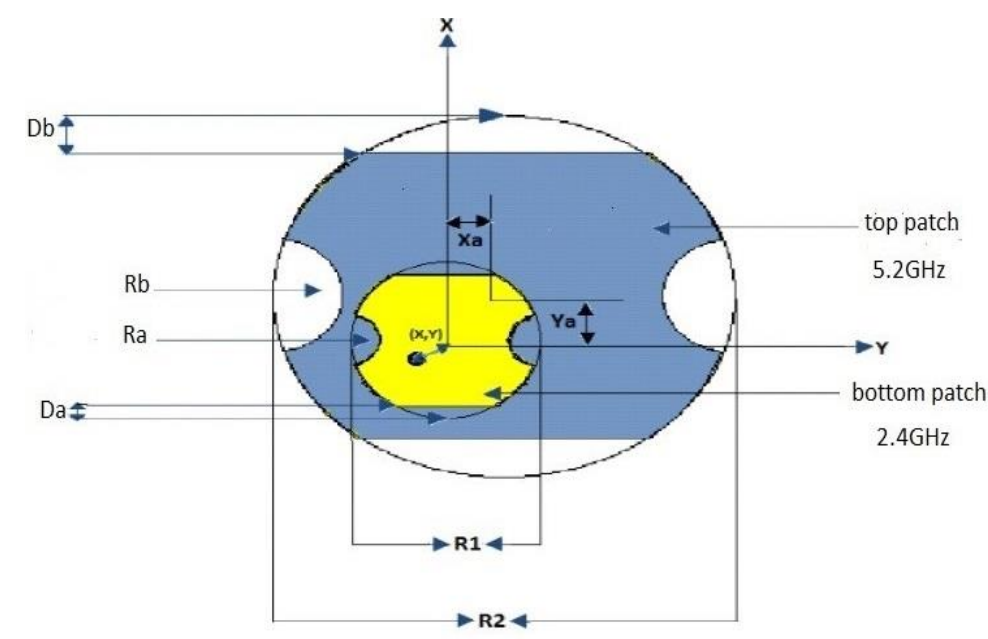

Figure 1. Top View of CP Antenna

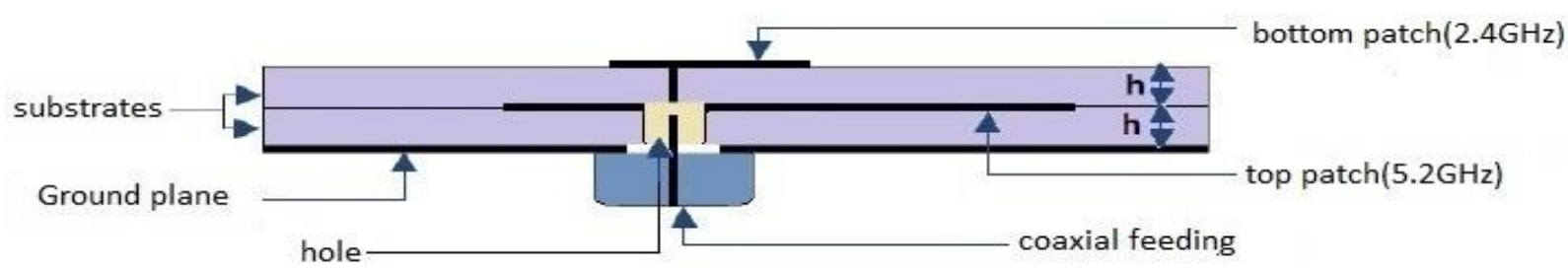

Figure 2. Side View of CP Antenna 


\section{RADIATION DESIGN}

CST MW studio was the tool used for analyzing of the stimulated antenna. Return loss is the reflection of signal power caused by hindrance of an object in the transmission line or optical fiber. It is mostly expressed in $\mathrm{dB}$ and used as a ratio of the transmitted signal power and receiver signal power [13]. In order for the antenna to radiate comprehensively [12], return loss should be <-10dB. Different Parameters required for the design of Dual Band CP Antenna Table 1.

Table 1. Different Parameters required for the design of Dual Band CP Antenna

\begin{tabular}{|c|c|c|c|}
\hline $\begin{array}{c}\text { Antenna Geometric } \\
\text { Parameters }\end{array}$ & variables & $\begin{array}{c}\text { starting } \\
\text { value(mm) }\end{array}$ & $\begin{array}{c}\text { final } \\
\text { value }(\mathbf{m m})\end{array}$ \\
\hline height of substrate & $\mathrm{H}$ & 1.6 & 1.6 \\
\hline width of substrate & Subx & 60 & 60 \\
\hline length of substrate & Suby & 60 & 60 \\
\hline larger patch radius & $\mathrm{R} 2$ & 16.4 & $16.85 *$ \\
\hline smaller patch radius & $\mathrm{R} 1$ & 6.8 & 6.8 \\
\hline truncation of larger patch & $\mathrm{Rb}$ & 5 & $5.3 *$ \\
\hline truncation of smaller patch & $\mathrm{Ra}$ & 2.2 & $2.03 *$ \\
\hline cutting of larger patch & $\mathrm{Db}$ & 3.8 & 3.8 \\
\hline cutting of smaller patch & $\mathrm{Da}$ & 1 & 1 \\
\hline height of ground & Mt & 0.028 & 0.028 \\
\hline $\begin{array}{l}\text { inner radius of outer } \\
\text { conductor }\end{array}$ & $\mathrm{Hg}$ (ground hole) & 1.675 & 1.675 \\
\hline outer radius of inner hole & Hp(probe hole) & 1 & 1 \\
\hline feeding point & $\mathrm{X}, \mathrm{Y}$ & $1.3,1.3$ & $1.1 *, 1.1 *$ \\
\hline $\begin{array}{l}\text { centre of small patch from } \\
\text { the centre of larger patch }\end{array}$ & $\mathrm{Xa}, \mathrm{Ya}$ & $3.9,3.9$ & $3.9,3.9$ \\
\hline
\end{tabular}

*values are supposed to be varied

\section{RESULTS AND ANALYSIS}

Graph in Figure 3 has a RL of $<-10 \mathrm{~dB}$ at around 2.4 and $5.2 \mathrm{GHz}$ frequencies. Directivity is a key parameter for the antenna's designing process. Enabling the far field using RCS and choosing the wave-guide port correctly, directivity of the desired antenna in the 2.4 and $5.2 \mathrm{GHz}$ can be predicted [11]. From the figure 4 and 5 it can be concluded that the maximum directivity of the desired antenna is along $\mathrm{z}$-axis. The ratio of electric field along $\mathrm{x}$ and $\mathrm{y}$ directions is determined by the axial ratio [13]. Axial ratio must be $<3 \mathrm{~dB}$ in order to obtain circular polarization of Dual band CP micro-strip antenna [12]. The graph in Figure 6 illustrates the axial ratio vs frequency is $\angle 3 \mathrm{~dB}$ for $2.4 \mathrm{GHz}$ and $5.2 \mathrm{GHz}$ and thus it also confirms that our bands are circular polarized. If in the case, they were $>3 \mathrm{~dB}$ then they were not supposed to be called as $\mathrm{CP}$.

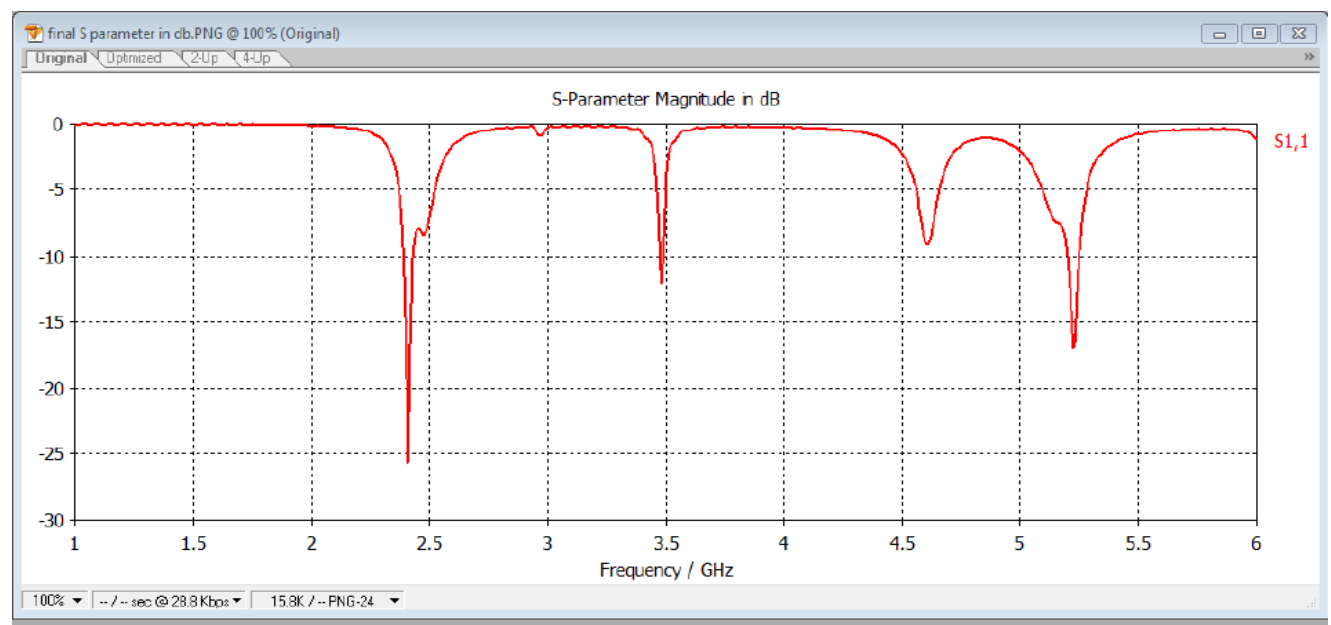

Figure 3. Return Loss vs Frequency 


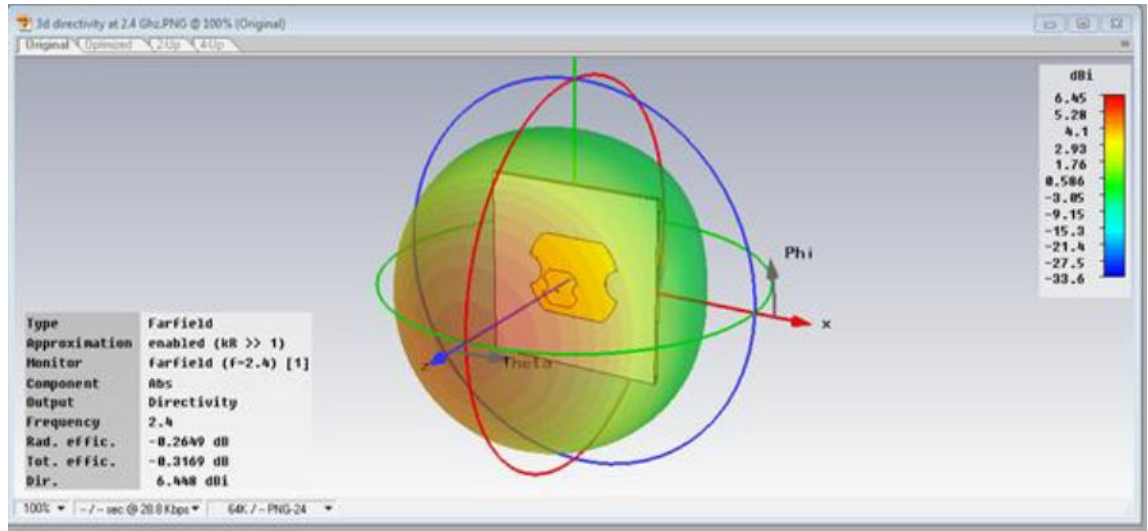

Figure 4. Directivity of CP Antenna at $2.4 \mathrm{GHz}$

\section{DISCUSSUION ON THE RESULTS}

Changing the antenna parameters might give different results. As far as the feeding point is changed, a change in s parameter is also being observed [14]. Figure 7 and 8 represent change in the return loss of SParameters as the feeding points are changed from 1.33 to 1.1 mentioned in Table 1.Changing the truncation parameters $\mathrm{Ra}, \mathrm{Rb}$ bring variation in the axial ratio curve of Figure 9, affecting the intended polarization. Similarly, if the radius of patch changes, bands move from one place to another [15]. In the Figure 10 it can be noticed that the frequency band of $2.4 \mathrm{GHz}$ move slightly to $2.48 \mathrm{GHz}$ and similarly $5.2 \mathrm{GHz}$ to $5.4 \mathrm{GHz}$ respectively.

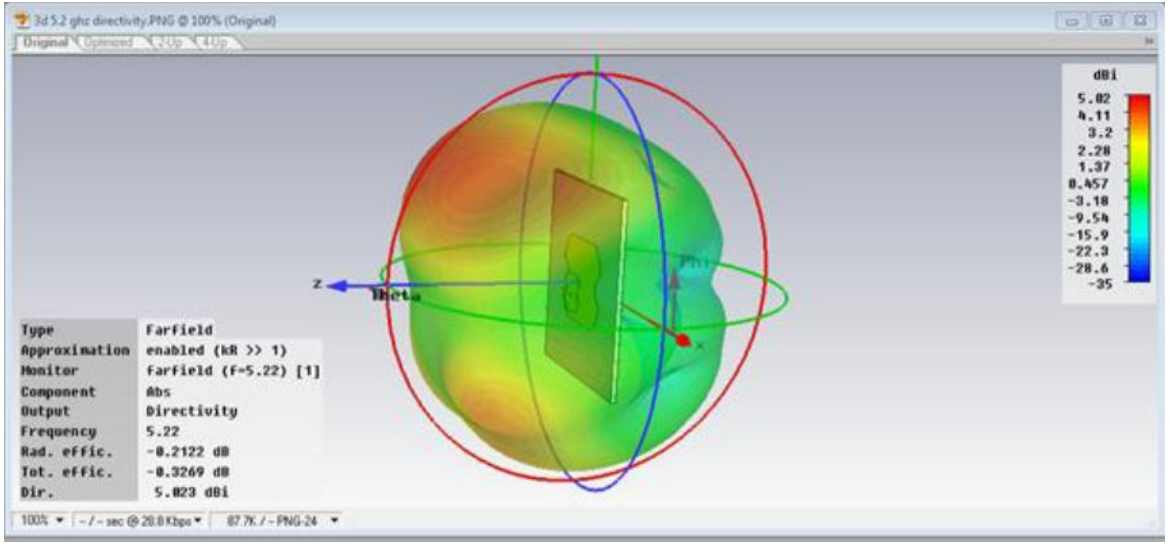

Figure 5. Directivity of CP Antenna at $5.2 \mathrm{GHz}$

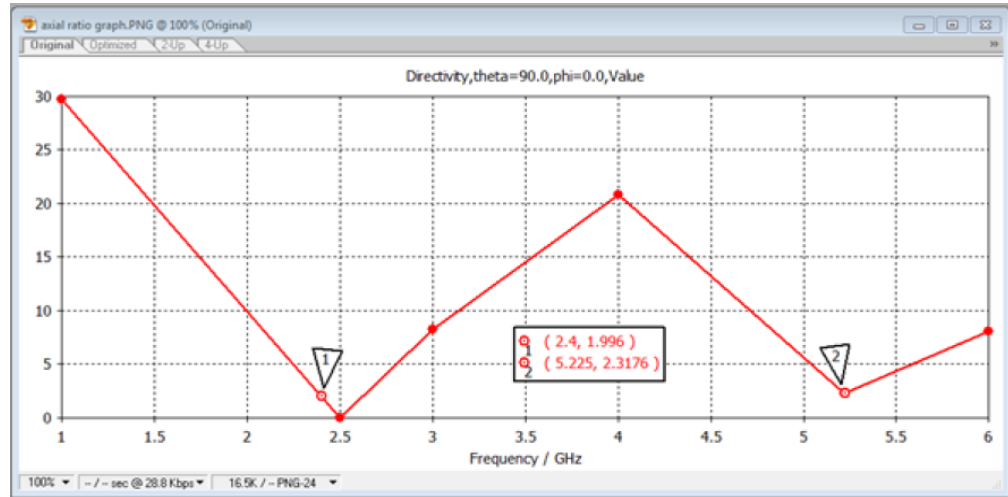

Figure 6. Axial ratio vs Frequency 


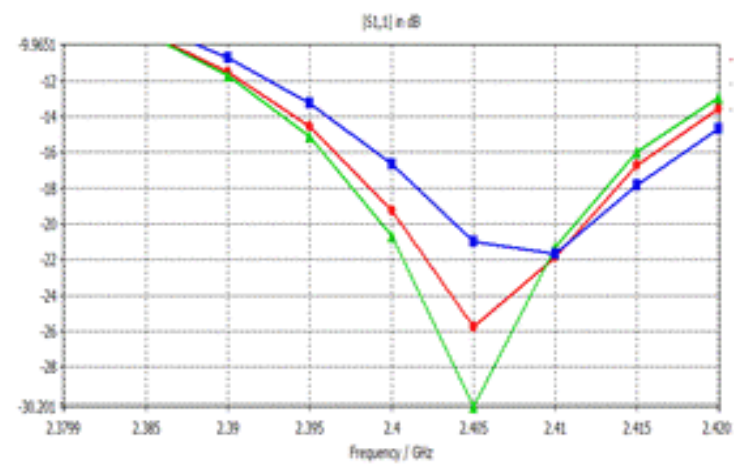

Figure 7. Variation of S-Parameter at $2.4 \mathrm{GHz}$

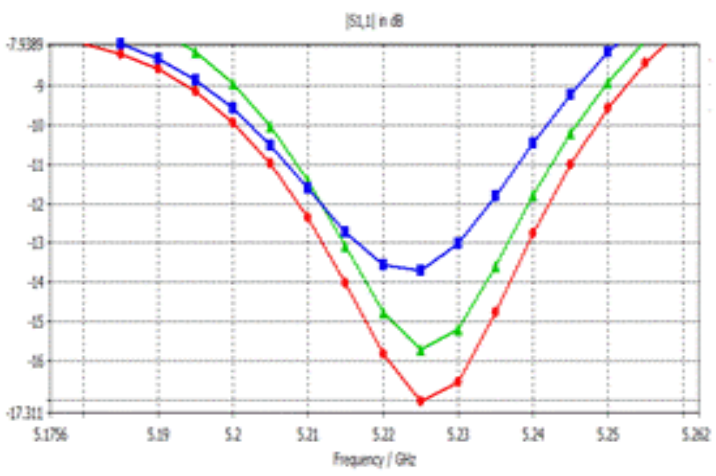

Figure 8. Variation of S-Parameter at $5.2 \mathrm{GHz}$

\section{CONCLUSIONS}

Dual band with $\mathrm{CP}$ was successfully achieved in design of $\mathrm{CP}$ antenna through these operating bands of 2.4 and $5.2 \mathrm{GHz}$. The feed point, patch size and truncations were varied and were checked through experimental results. Two patches instead of single patch with the same characteristics employed on the basis of difference in their results. The proposed antenna produced desirable results throughout the chosen operating bands. The most significant result that came out was the axial ratio curve revealing the circular polarization and its value was 1.996 at $2.4 \mathrm{GHz}$ and 2.31 at $5.2 \mathrm{GHz}$, which is a very good positive result for the CP antenna design.

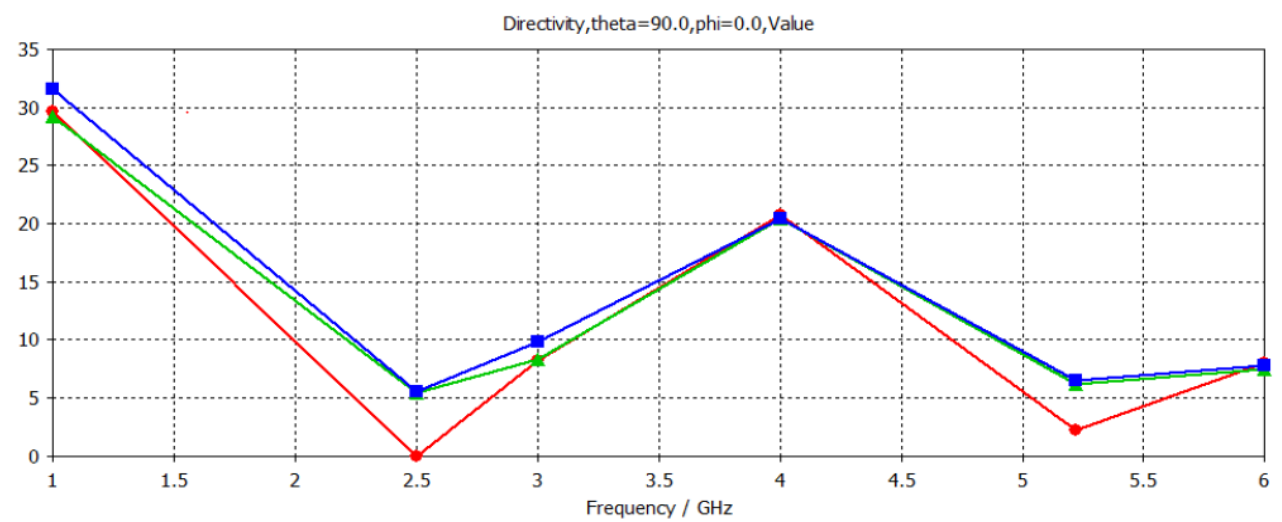

Figure 9. Variation in Axial ratio vs Frequency

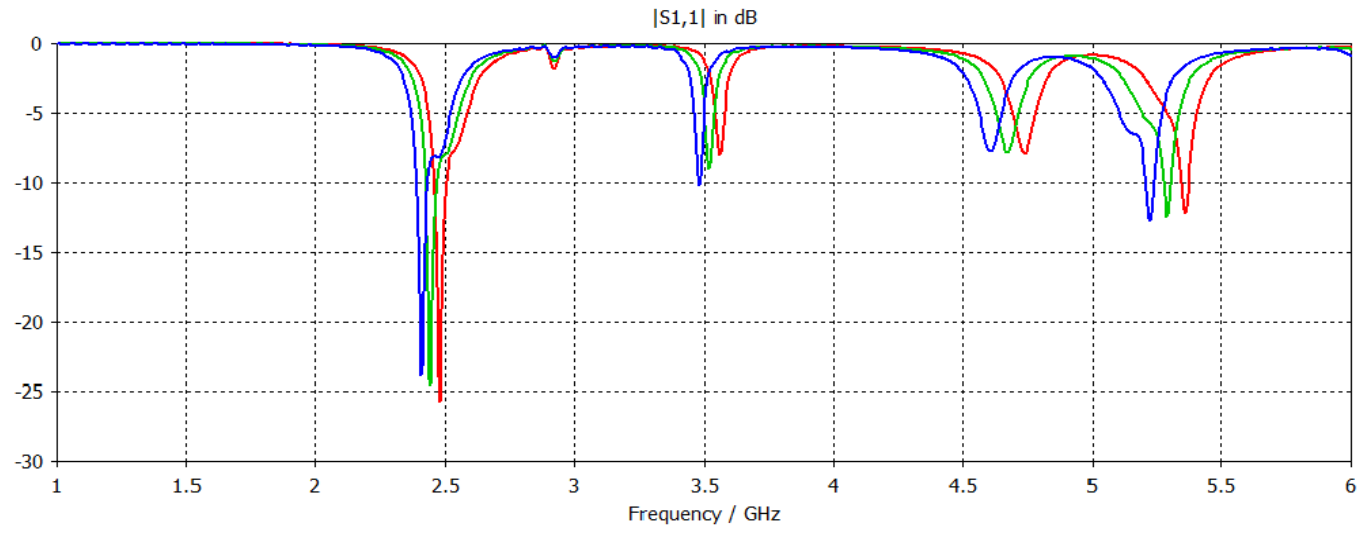

Figure 10. Variation of S- Parameter at different frequencies 


\section{FUTURE WORK SUGGESTIONS}

In future, the design of this antenna can be modified by making it suitable for other upcoming WLAN standards. Length and breadth of the patch can be varied more and more to achieve the desired higher gain capabilities. Bandwidth can also be increased by using another type of feeding technique [16] i-e coaxial probe with capacitive feeding. Extra band which is not circular polarized but present in operating range can also be removed by proper truncation of circular patch.

\section{REFERENCES}

[1] K. P. Wong, K. L., ” Dual-band circularly-polarized square micro-strip antenna”, IEEE Transactions on Antennas and Propagation, 2001, vol. 49, p. 377-382.

[2] Liao, W., Chu, Q.-X," Dual-band circularly polarized micro-strip antenna with small frequency ratio", Progress in Electro-magnetic Research Letters, 2010, vol. 15, p. 145-152.

[3] Jou C. F., J.-W. Wu, and C.-J. Wang, "Novel broadband monopole antennas with dual-band circular polarization ”,IEEE Trans.on Ant Antennas and Propag., Vol. 57, No. 4, 1027-1034, Apr. 2009.

[4] Jeevanandham .N., Nasimuddin, K. Agarwal, and A. Alphones, "Dual-band circularly polarized hexagonal-slot antenna," European Microwave Conference (EuMC 2012), 508-511, Amsterdam RAI, The Netherlands, Oct. 29Nov. 2, 2012.

[5] X. L. Bao, M. J. Ammann, "Mono filar spiral slot antenna for dual-frequency dual-sense circular polarization "IEEE Trans. Antennas Propag. vol. 59 no. 8 pp. 3061-3065 Aug. 2011.

[6] Y.-Y. Chen, Y.-C.Jiao ,G. Zhao ,F. Zhang Z.L. Liao, Y. Tian, "Dual-band dual-sense circularly polarized slot antenna with a C-shaped grounded strip",IEEE Antennas Wireless Propag. Lett. vol. 10 pp. 915-918 2011.

[7] Y. Shao, Z. Chen "A design of dual-frequency dual-sense circularly-polarized slot antenna "IEEE Trans. Antennas Propag. vol. 60 no. 11 pp. $4992-4997$ Nov. 2012.

[8] X. Rui, J. Li, K. Wei "Dual-band dual-sense circularly polarised square slot antenna with simple structure" ,Electron. Lett. vol. 52 no. 8 pp. 578-580 Apr. 2016.

[9] J.-D. Zhang, L. Zhu, N.-W. Liu, W. Wu "Dual-band and dual-circularly polarized single-layer micro-strip array based on multi resonant modes" IEEE Trans. Antennas Propag.vol. 65 no. 3 pp. 1428-1433 Mar. 2017.

[10] Z.Whang, R.She, J.Han, S.Fang, Y.Liu " Dual-Band Dual Sense Circularly polarized stacked patch antenna with a small frequency ratio for UHF RFID Reader Applications" IEEE Open access journal vol.5 pp. 15260-15270 Jul. 2017.

[11] James J.R, P.S. Hall (1989). Handbook of Micro-strip Antennas, Peter Peregrinus. ISBN 0863411509.

[12] OOI, T. S., Rahim, S. K. A., Koh, "B. P. $2.45 \mathrm{GHz}$ and $5.8 \mathrm{GHz}$ compact dual-band circularly polarized patch antenna",Journal of Electromagnetic Waves and Applications, Vol24,1473-1482,Apr,2012.

[13] Pozar, David .M (2005).Microwave Sons. Engineering, second edition, Johan Wiley \& ISBN978-0-471-44878-5.

[14] P. Nayeri, K.-F. Lee, A. Z. Elsherbeni, and F. Yang, “Dual-band circularly polarized antennas using stacked patches with asymmetric U-slots,’ IEEE Antennas Wireless Propag. Lett., vol. 10, pp. 492-495, 2011.

[15] C. Chen and E. K. N. Yung, "Dual-band dual-sense circularly-polarized CPW-fed slot antenna with two spiral slots loaded,"' IEEE Trans. Antennas Propag., vol. 57, no. 6, pp. 1829-1833, Jun. 2009.

[16] J.-D. Zhang, W. Wu, and D.-G. Fang, "Dual-band and dual-circularly polarized shared-aperture array antennas with single-layer substrate,’’ IEEE Trans. Antennas Propag., vol. 64, no. 1, pp. 109-116, Jan. 2016.

\section{BIOGRAPHY OF AUTHOR}

\begin{tabular}{|l|l|}
\hline & $\begin{array}{l}\text { Syed Muhammad Ali doing MS in Computer System Engineering with specialization in Mobile } \\
\text { Communication and Networks from University of Engineering and Technology, Peshawar, } \\
\text { Pakistan. His bachelor's degree was in Electrical Engineering having major in Communication } \\
\text { Engineering. His main area of research interests include Machine to Machine Communication in } \\
\text { Mobile Communications, Upcoming 802.11 standards, Probalistic theory in Network modeling } \\
\text { and Analysis, Digital Control Systems and Stochastic Simulation for Communication Networks. } \\
\text { He is currently doing job of Access Network Engineer at Augere Pvt Ltd. }\end{array}$ \\
\hline
\end{tabular}

